\title{
Endoscopy-guided vitreoretinal surgery following penetrating corneal injury: a case report
}

This article was published in the following Dove Press journal:

Clinical Ophthalmology

31 July 2010

Number of times this article has been viewed

\section{Motoko Kawashima' \\ Shinichi Kawashima² \\ Murat Dogru',3 \\ Makoto Inoue ${ }^{4}$ \\ Jun Shimazaki ${ }^{1,5}$}

'Department of Ophthalmology, Tokyo Dental College, Chiba, Japan; ${ }^{2}$ Department of Ophthalmology, International University of Health and Welfare, Tokyo, Japan; ${ }^{3}$ Department of Ocular Surface and Visual Optics, Keio University School of Medicine,

Tokyo, Japan; ${ }^{4}$ Kyorin Eye Center,

Tokyo, Japan; ${ }^{5}$ Department of

Ophthalmology, Keio University

School of Medicine, Tokyo, Japan
Correspondence: Motoko Kawashima Department of Ophthalmology, Tokyo Dental College, 5-I I-I3 Sugano, Ichikawa, Chiba, Japan 27285I3

Email motoko326@gmail.com
Introduction: Severe ocular trauma requires emergency surgery, and a fresh corneal graft may not always be available. We describe a case of perforating eye injury with corneal opacity, suspected endophthalmitis, and an intraocular foreign body. The patient was successfully treated with a two-step procedure comprising endoscopy-guided vitrectomy followed by corneal transplantation. This surgical technique offers a good option to vitrectomy with simultaneous keratoplasty in emergency cases where no graft is immediately available and there is the possibility of infection due to the presence of a foreign body.

Case presentation: A 55-year-old Japanese woman was referred to our hospital with a perforating corneal and lens injury sustained with a muddy ferrous rod. Primary corneal sutures and lensectomy were performed immediately. Vitreoretinal surgery was required due to suspected endophthalmitis, vitreous hemorrhage, retinal detachment, dialysis and necrosis of the peripheral retina. Instead of conventional vitrectomy, endoscopy-guided vitreous surgery was performed with the Solid Fiber Catheter AS-611 (FiberTech, Tokyo, Japan) due to the presence of corneal opacity and the unavailability of a donor cornea. The retina was successfully attached with the aid of a silicon oil tamponade. Following removal of the silicon oil at 3 months after surgery, penetrating keratoplasty and intraocular lens implantation with ciliary sulcus suture fixation were performed. At 6 months after penetrating keratoplasty, the graft remained clear and visual acuity was 20/40.

Conclusion: Primary endoscopic surgery for vitreoretinal complications in eyes with perforating injury performed prior to penetrating keratoplasty appears to be advantageous in terms of avoiding damage to the corneal endothelium.

Keywords: vitreoretinal surgery, emergency, foreign body

\section{Introduction}

Severe ocular trauma requires emergency surgery, and a fresh corneal graft may not always be available. We describe a case of perforating eye injury with corneal opacity, possible endophthalmitis, and an intraocular foreign body successfully treated with a two-step procedure comprising endoscopy-guided vitrectomy followed by corneal transplantation.

\section{Case presentation}

A 55-year-old Japanese woman was referred to our hospital with a perforating corneal and lens injury sustained while carrying a muddy ferrous rod. On initial examination, her best-corrected visual acuity (BCVA) was light perception in the right eye. Slit lamp examination revealed a penetrating corneal and lens injury in the 
5.30 o'clock position on the temporal side, but no foreign bodies. The anterior chamber was flat, with iris herniation and hyphema. Primary corneal sutures, anterior vitrectomy and lensectomy were performed as emergency procedures. Written informed consent was obtained from the patient for the surgical procedures, examinations, and treatment modalities throughout her admissions and follow-up examinations. All the procedures complied with the tenets of the Declaration of Helsinki. No foreign bodies were discovered with preoperative X-rays or intraoperatively. The patient was discharged after 6 days and prescribed topical levofloxacine qid (Cravit ${ }^{\circledR}$, Santen Pharmaceutical Co, Osaka, Japan), betametasone qid (Rinderon ${ }^{\circledR}$, Shionogi, Osaka, Japan) and tropicamide plus phenylephrine hydrochloride tid (Mydrin $\mathrm{P}^{\circledR}$, Santen). Postoperative visual acuity was hand motion in the right eye and intraocular pressure was within the normal limits. Fundoscopy and B-mode ultrasonography revealed no retinal detachment or foreign bodies. Four days after being discharged, the patient complained of ocular pain. A follow-up examination at the outpatient clinic revealed corneal edema, hyphema, and the presence of cells in the anterior chamber. Intraocular pressure (IOP) was $45 \mathrm{mmHg}$. In addition to oral acetazolamide at $1000 \mathrm{mg} /$ day $\left(\right.$ Diamox $^{\circledR}$, Sanwa Kagaku Kenkyusho, Nagoya, Japan) the patient was also prescribed $0.5 \%$ timolol bid (Timoptol ${ }^{\circledR}$, Santen, Japan) and $1 \%$ brinzolamide eye drops bid $\left(\right.$ Azopt $^{\circledR}$, Alcon Japan, Tokyo, Japan). The patient received $300 \mathrm{~mL}$ of IV mannitol over the following 11 days due to uncontrollable intraocular pressure. Increase in corneal edema, the appearance of +++ cells and fibrin exudates in the anterior chamber led to a tentative diagnosis of endophthalmitis with secondary ocular hypertension (Figure 1). Detailed observation of

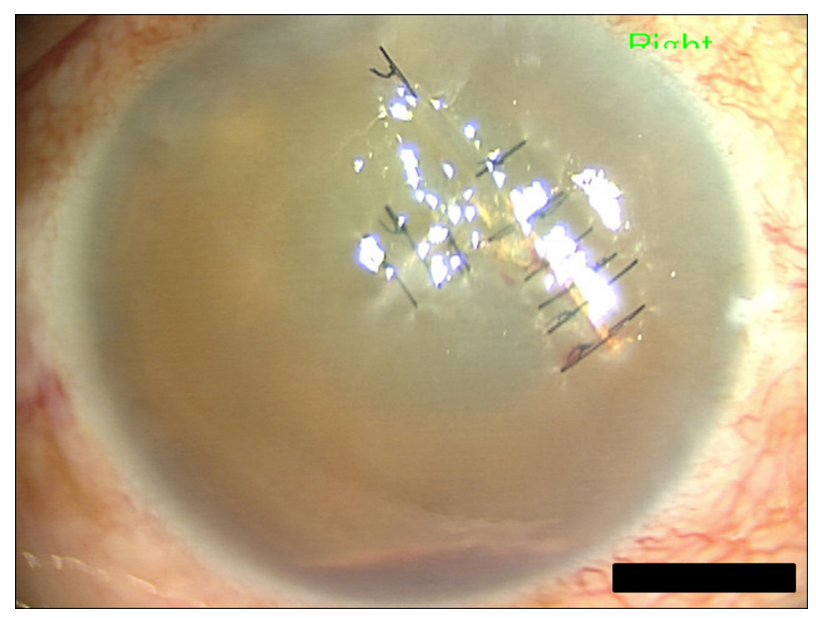

Figure I Photograph of anterior segment just prior to endoscopy-guided vitrectomy. Note severe corneal edema, hyphema, +++ cells and fibrin exudates in anterior chamber, leading to tentative diagnosis of endophthalmitis with secondary glaucoma. the posterior segment was not possible with fundoscopy. Vitreous hemorrhage was diagnosed by B-mode ultrasound echography.

Vitreoretinal surgery and removal of the vitreous hemorrhage were planned for suspected endophthalmitis. Instead of conventional vitrectomy with simultaneous keratoplasty, endoscopy-guided vitrectomy was considered due to the presence of corneal opacity, the lack of availability of a donor cornea, and the potential for excessive corneal endothelial damage to occur during a combined vitrectomy and keratoplasty procedure. Endoscopy-guided vitreous surgery was performed using the Solid Fiber Catheter AS-611 (FiberTech Corp, Tokyo, Japan). Three 20-G vitrectomy ports were created. Endoscopic examination revealed diffuse whitening of the vitreous body, retinal edema, dot hemorrhages, and multiple foci of peripheral retinal dialysis extending 360 degrees. Endoscopic examination also revealed a 3.5-mm linear brown elastic object associated with white surrounding fibrin and an area of retinal necrotic dialysis located anterior to the equator in the 5.30 o'clock position. Areas where there was retinal dialysis or retinal necrosis peripheral to the penetration site were treated with green YAG laser endophotocoagulation and gas-fluid exchange, followed by a 4.2-mL silicon oil tamponade. The exchange fluid contained $20 \mu \mathrm{g} / \mathrm{mL}$ vancomycin (Shionogi) and 40 $\mu \mathrm{g} / \mathrm{mL}$ ceftazidime hydrate (Modacin ${ }^{\circledR}$, GlaxoSmithKline, Tokyo, Japan). Intravitreal injection of $10 \mathrm{mg} / \mathrm{mL}$ vancomycin and $20 \mathrm{mg} / \mathrm{mL}$ ceftazidime hydrate was also carried out. Figure 2 shows the post-treatment features of the area observed by endoscopy near the penetrating injury

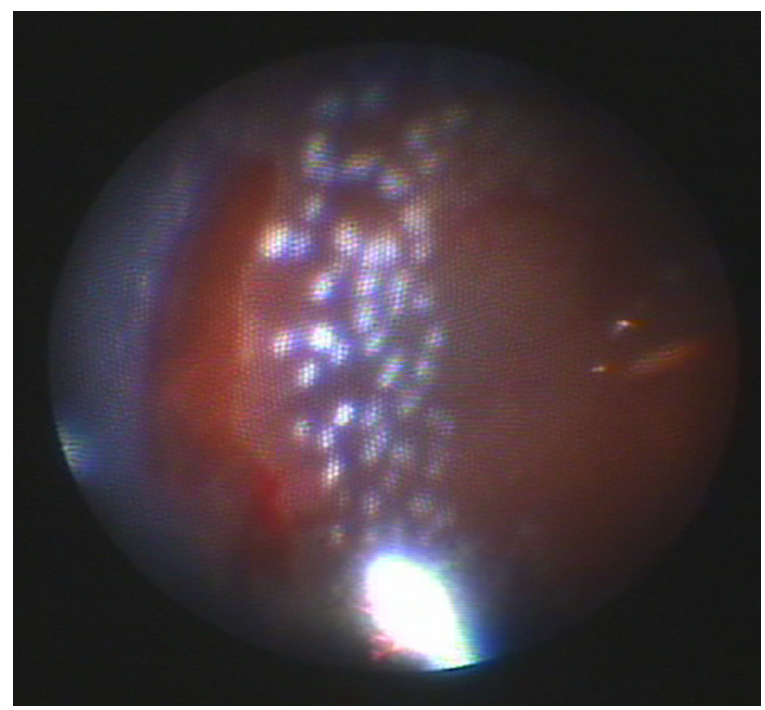

Figure 2 Intraoperative endoscopic view. Note clear view of necrotic retinal break treated with endophotocoagulation after removal of small foreign body in 5.30 o'clock position anterior to equator in peripheral retina. 
where the foreign body and peripheral retinal dialysis were found. Japanese iridectomy was performed at 6 o'clock, followed by closure of the vitrectomy ports with $7 / 0$ dexon sutures. Subconjunctival injection of $10 \mathrm{mg} / \mathrm{mL}$ vancomycin and $20 \mathrm{mg} / \mathrm{mL}$ ceftazidime hydrate and ofloxacin ophthalmic ointment (Tarivid ${ }^{\circledR}$, Santen) were carried out. No pathological organisms, including bacteria or fungi, were identified in microbiological cultures from the extracted intraocular foreign body or vitreous sample. Landolt uncorrected visual acuity in the right eye was 20/400 and IOP was $16 \mathrm{mmHg}$ without administration of anti-glaucoma drops at 3 months after surgery. No cells were observed in the anterior chamber. The silicon oil tamponade had facilitated successful attachment of the retina.

The decision was made to remove the silicon oil at 3 months postoperatively. The patient was registered in a waiting list for domestic donors. Penetrating keratoplasty and intraocular lens implantation with ciliary sulcus fixation were performed when a local donor graft became available one year later. The patient was prescribed topical levofloxacine qid (Cravit), topical betamethasone qid (Rinderon), and $0.1 \%$ topical sodium hyaluronate (Hyalein ${ }^{\circledR}$, Santen) eye drops qid. At 6 months postoperatively, the graft remained clear and BCVA was $20 / 100+1.25-5.095$. The patient was prescribed a spheric $+3.50 \mathrm{D}$ hard contact lens with a base curvature of $8.6 \mathrm{~mm}$ and a diameter of $9.8 \mathrm{~mm}$ due to irregular astigmatism. The contact lens corrected visual acuity 5 months later was 20/40. Intraocular pressure in the right eye was $16 \mathrm{mmHg}$. Endothelial cell density was $1968 / \mathrm{mm}^{2}$ (Figure 3).

\section{Discussion}

A temporary keratoprosthesis during vitreoretinal surgery may be used in cases where the eye has sustained a

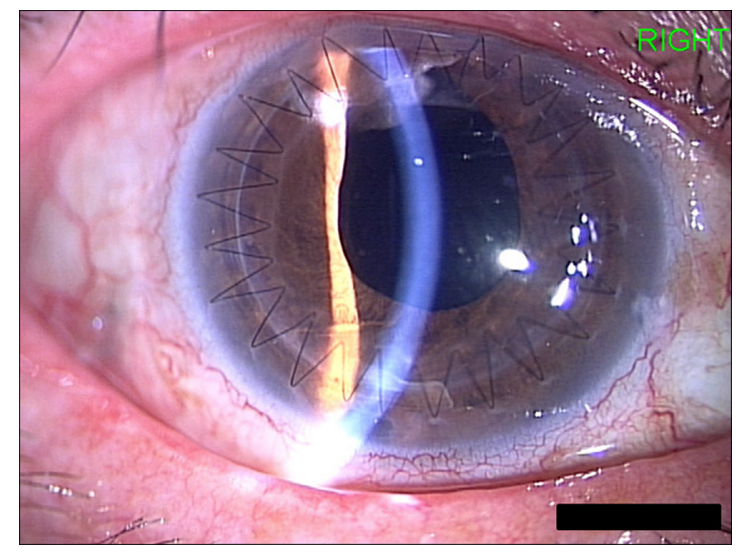

Figure 3 Photograph of anterior segment at 8 months after keratoplasty and ciliary sulcus fixated intraocular lens implantation. Note that graft remained clear with $\mathrm{HCL}$ corrected visual acuity of $20 / 40$. perforating corneal injury and potential vitreoretinal pathologies may be hidden from view. ${ }^{1}$ Combined vitrectomy and simultaneous keratoplasty have been reported to be beneficial. ${ }^{2}$ However, an open-sky procedure in a perforated eye may cause intraoperative and postoperative complications, including suprachoroidal hemorrhage and early corneal graft failure. ${ }^{3}$ Therefore, a closed-eye procedure is believed to be safer where perforation has occurred. In addition, when endophthalmitis may have occurred following traumatic injury, the risk of primary graft failure is higher; and subsequent corneal regrafting also carries a higher risk of graft rejection due to persistent inflammation. In the current case, a favorable surgical outcome with useful vision and transparent corneal graft with no complications or episodes of infection and/or rejection was observed.

The intraoperative endoscopic approach adopted here allowed observation of the ciliary sulcus, pars plana, and vitreous base, enabling us to observe an intraocular foreign body in a perforated eye that might have gone undetected otherwise. Although the endoscopic view itself is non-stereoscopic, shadows created by intraocular surgical instruments and endoscopic illumination may provide pseudo-stereoscopic images, allowing estimation of the distance between the intraocular surgical instruments and the retina. However, this indirect sensing of space and dimension differs from that achieved with an operating microscope. Therefore, greater caution may be required in estimating space and dimension in endoscopic procedures during surgery. Where no corneal transplantation is carried out, there may be problems with observing the eye during postoperative follow-up due to corneal opacity. In addition, endoscopic vitrectomy and subsequent keratoplasty have the disadvantage of requiring a longer time for visual rehabilitation to occur while the patient waits to undergo a corneal transplantation. However, this two-step procedure comprising endoscopy-guided vitrectomy followed by corneal transplantation offers a useful option to vitreoretinal surgery with simultaneous penetrating keratoplasty in trauma cases where there is severe penetration of the anterior segment, allowing avoidance of excessive damage to the corneal endothelium and initial graft failure.

\section{Conclusion}

We described a case of perforating eye injury with corneal opacity and possible endophthalmitis and an intraocular foreign body successfully treated with a two-step procedure comprising endoscopy-guided vitrectomy followed by corneal transplantation. 


\section{Disclosure}

The authors declare that they have no competing interests.

\section{References}

1. Eckardt C. A new temporary keratoprosthesis for pars plana vitrectomy. Retina. 1987;7:34-37.
2. Koenig SB, McDonald HR, Williams GA, Abrams GW. Penetrating keratoplasty after placement of a temporary keratoprosthesis during pars plana vitrectomy. Am J Ophthalmol. 1986;102:45-49.

3. Garcia-Valenzuela E, Blair NP, Shapiro MJ, et al. Outcome of vitreoretinal surgery and penetrating keratoplasty using temporary keratoprosthesis. Retina. 1999;19:424-429.

\section{Publish your work in this journal}

Clinical Ophthalmology is an international, peer-reviewed journal covering all subspecialties within ophthalmology. Key topics include: Optometry; Visual science; Pharmacology and drug therapy in eye diseases; Basic Sciences; Primary and Secondary eye care; Patient Safety and Quality of Care Improvements. This journal is indexed on
PubMed Central and CAS, and is the official journal of The Society of Clinical Ophthalmology (SCO). The manuscript management system is completely online and includes a very quick and fair peer-review system, which is all easy to use. Visit http://www.dovepress.com/ testimonials.php to read real quotes from published authors. 